\title{
ANOPHTHALMIA AND MALDEVELOPMENT OF THE EYES: FOUR CASES IN THE SAME FAMILY
}

\author{
BY
}

\section{LEWIS MCMILlan, M.D.,} HON. SURGEON GLASGOW EYE INFIRMARY, OCULIST TO THE GLASGOW CORPORATION

While holidaying in the Highlands in August of 1919, I was asked by the parochial authorities to report on the condition of the eyes of the family of A. C., a labouring man dwelling in the Benderloch.

The parents were young, healthy-looking individuals, and lived in a cottage on the loch-side. The external appearance of their eyes was quite normal, and they had no complaint of visual defect. Apart from the condition of their eyes the four children appeared quite healthy and well developed. The local doctor, Dr. McNichol, who visited the house with me, informed me that there had been no inflammation of, or discharge from, the children's eyes at or after birth. The appearance of their eyes was entirely one of underdevelopment. So far as we could ascertain there had been no similar condition of the eyes in the parentage on either side.

C. C., female, 5 years of age. The right eye was undeveloped, the cornea absent, and the eye blind. The left eye was more developed, the cornea was clear, and there was a downward coloboma iridis congenitalis. The child was able to distinguish and name correctly a penny-piece held out to her. The mother stated that the child could see to lift an ordinary pin from the floor. With the means at my disposal I was unable to define clearly the details of the fundus oculi.

J. C., male, 3 years of age, was absolutely blind. The right socket was empty, anophthalmos, and the cavity was contracted. The left eyeball was undeveloped, the cornea being absent.

C. C., male, 2 years of age. This boy was also practically blind. A small dark spot in the centre of the front of the right eyeball represented the cornea, and through this light and darkness could be distinguished. The left socket was empty, another case of anophthalmos.

M. C., 1 year old. The right eye resembled those seen in the other children, undeveloped, opaque, and blind. The left eye was the most normal-looking eye seen in any of the children. It was clear, bright, and healthy looking. The iris was fully developed, the pupil circular, and responding well to light. The details of the interior of the eye could be clearly seen through the ophthalmoscope. The child could see well enough to take hold of objects held out to her.

I recommended that an attempt should be made to educate the eldest and the youngest children in the ordinary way, and that the second and third should be educated in a blind asylum. 
The parents are young and evidently prolific. Whatever the prenatal cause may be, the outlook for any future children is to me simply appalling.

\section{INJURIES FROM HIGH EXPLOSIVE* BY \\ J. Lockhart Gibson, M.D.Edin., M.R.C.S.Eng. BRISBANE}

(1) Private C., aged 26.--L.E. 'Traumatic cataract caused by high explosive, July, 4, 1918. Dense occluding remains of lens and capsule in pupil. Was told in England "that nothing could be done to improve sight."

Jan. 20.-A small comparatively thin central part of occluding membrane allowed a small opening to be needled in it, resulting in corrected vision $6 / 12$ and 2 of $6 / 9$ and J. i.

The other eye (right) had been broken up by the force of the explosion, and was quite blind and irritable when he came to Brisbane. Its enucleation gave much relief. The patient also lost one leg above the knee.

He had been so impressed by the belief that nothing could be done that he naturally hesitated to let me try.

The force of the explosion was exerted in this case on the lens, and the fundus escaped.

He owes the result largely to his youth.

(2) Private C., aged 22.- Note disappearing siderotic spots on cornea and schlera after removal of small steel particles, after thirty months' of residence. One eye (left) shows a rupture of the choroid to upper inner side of the disc, as well as some fine opaque striae in the inner half of the lens. Its corrected vision is $6 / 9$ and one letter of $6 / 6$.

The other eye (right) shows a rupture of the choroid close to the macula, and it only sees fingers at one yard.

The ruptures of choroid due to "contre coup."

The lenses escaped injury.

Note many steel particles under the skin of the face.

(3) Gunner W.-Numerous powder marks in neighbourhood of eyes, and forehead, and in conjunctivae. Double traumatic cataract. Dense remains of broken up lens and capsule occluding both pupils. Taught Braille at St. Dunstan's, and sent back as a blinded soldier. Counting fingers at 2 feet with right eye, at 6 inches with left eye. Right eye sees now with correction 6/9 and J. i. Left eye opacity still very dense in spite of two needlings,

* Card specimens shown at the 11th Australasian Medical Congress, Brisbane, August, 1920. 